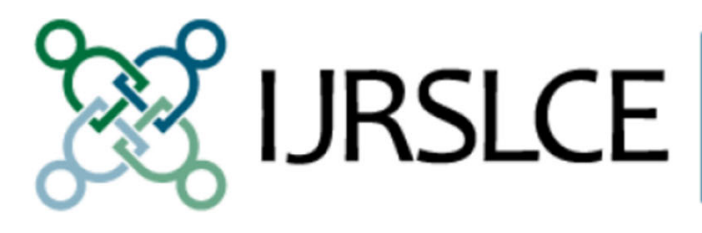

International Journal

for Research on

Service-Learning \&

Community Engagement

\title{
Works in Progress: Coming in the Fall 2016 Edition
}

\section{Katrina Norvell}

\section{J. R. Jamison}

This article was originally published at:

https://journals.sfu.ca/iarslce/index.php/journal/article/view/163/87

Recommended Citation

Norvell, K., \& Jamison, J. R. (2015). Works in Progress: Coming in the Fall 2016 Edition. International Journal of Research on Service-Learning and Community Engagement, 3(1), Article 23. 


\title{
Works in Progress: Coming in the Fall 2016 Edition
}

\author{
Katrina Norvell \\ Roger Williams University \\ J. R. Jamison \\ Indiana Campus Compact
}

\section{Section Co-Editors}

Emerging scholars in the field of community engagement in higher education will develop the future trajectory of our shared work based on innovative theoretical frameworks and subsequent research findings. To support IARSLCE's mission of supporting new scholars in service-learning and community engagement, IJRSLCE's "Works in Progress" section will publish drafts of research studies or manuscripts in progress along with feedback and critiques from scholars and IJRSLCE reviewers. This unique platform will allow a comprehensive review of up-and-coming work while providing a space for other emerging scholars in the field to understand the review and publication process.

The Works in Progress section will also serve as a platform for all scholars in the field who want to share their "ideas in progress" or white papers and essays that advance critical thinking and discussion on challenging and emerging topics related to community engagement scholarship. Submissions in this category of the Works in Progress section are intended to elicit responses that can also be published through IJRSLCE.

Please note: Draft research studies or manuscripts will appear in the journal with tracked changes and reviewer comments listed. Authors will have the opportunity to submit revised drafts to another section of IJRSLCE for potential publication in the following issue. If authors decide to submit revised articles to another journal, IJRSLCE will provide a copyright release record for your final product. Please contact IJRSLCE for further information. 